\title{
Isolation, identification, and degradation performance of a PFOA-degrading strain
}

\author{
L.B. Yi ${ }^{1,2}$, L.Y. Chai ${ }^{1}$,Y. Xie ${ }^{2}$, Q.J. Peng ${ }^{2}$ and Q.Z. Peng ${ }^{2}$ \\ ${ }^{1}$ School of Metallurgy and Environment, Central South University, Changsha, \\ China \\ ${ }^{2}$ College of Biology and Environmental Sciences, Jishou University, \\ Hunan Jishou, China \\ Corresponding authors: L.Y. Chai / Q.Z. Peng \\ E-mail: lychai@mail.csu.edu.cn / qzpengjsu@163.com
}

Genet. Mol. Res. 15 (2): gmr.15028043

Received November 11, 2015

Accepted January 18, 2016

Published May 6, 2016

DOI http://dx.doi.org/10.4238/gmr.15028043

ABSTRACT. The perfluorooctanoic acid (PFOA)-degrading strain YAB1 was isolated from the soil near a perfluorinated compound production plant through acclimation and enrichment culture, using PFOA as the sole carbon source. This strain was preliminarily identified as Pseudomonas parafulva based on colony morphology, physiological and biochemical features, and 16S rRNA gene sequencing. Using shaking flask fermentation, the maximum tolerable concentration of YAB1 on PFOA was found to be $1000 \mathrm{mg} / \mathrm{L}$. The optimal conditions for bacterial growth and PFOA degradation were $30^{\circ} \mathrm{C}, \mathrm{pH} 7,2 \%$ inoculum, and an initial PFOA concentration of $500 \mathrm{mg} / \mathrm{L}$. After $96 \mathrm{~h}$ of culture, the PFOA degradation rate determined by GC-MS analysis was $32.4 \%$. When $1 \mathrm{~g} / \mathrm{L}$ glucose was added to the inorganic salt culture medium, the degradation rate increased to $48.1 \%$. Glucose was the best exogenous carbon source for the degradation of PFOA. This study reports the degradation performance of PFOA-degrading bacteria.

Key words: Perfluorooctanoic acid; Screening; Identification; Degradation performance; Degradation rate 


\section{INTRODUCTION}

Perfluorinated compounds (PFCs) are linear-chain or branched-chain hydrocarbons whose hydrogen atoms are completely replaced by fluorine atoms. The C-F bond has high bonding energy $(110 \mathrm{kcal} / \mathrm{mol})$, which makes PFCs chemically and thermally stable, with high surface activity. Because of these features, PFCs are widely applied in industrial and agricultural production and domestic use. Perfluorooctanoic acid (PFOA), a representative PFC, is used not only in conventional industries such as the chemical industry, leather and textiles, machinery, and medicines, but also in high-technology industries such as aviation and aerospace, semiconductors, microelectronics, and the military (Kärrman et al., 2006; Chen et al., 2009). However, PFOA poses a considerable threat to human health and the environment because of its persistence, bioaccumulation, carcinogenicity, teratogenicity, mutagenicity, and endocrine disruption activity (So et al., 2004; Luebker et al., 2005; Grasty et al., 2005; Prevedouros et al., 2006). PFOA was included in the 2009 Stockholm Convention on Persistent Organic Pollutants.

At present, PFOA can be detected in the environment and in human blood around the globe. Therefore, finding a way to degrade PFOA is a major ecological concern. Studies show that conventional advanced oxidation processes (e.g., $\mathrm{O}_{3}, \mathrm{O}_{3} / \mathrm{UV}, \mathrm{O}_{3} / \mathrm{H}_{2} \mathrm{O}_{2}$, and Fenton's reagent) have limited promoting effect on PFOA degradation. Although some progress has been made with adsorptive separation and chemical degradation (Ochoa-Herrera et al., 2008; Zhao et al., 2011; Hori et al., 2012), these techniques are usually associated with highenergy consumption, complex procedures, low recovery, low-reaction rate, and secondary pollution. Bioremediation as a kind of economical and environment-friendly technique for treating PFOA contamination is gaining popularity. Xue et al. (2004) used enrichment culture to isolate two dominant strains, Z1 and Z3, that utilized fluorine-containing compounds as a carbon source. As shown by LC-MS analysis, the PFOA was bacterially defluorinated. Schröder (2003) and Meesters and Schröder (2004) reported that PFOA was degraded under anaerobic conditions using activated sludge in a sewage treatment plant, but the degradation efficiency was low. There are many other reports on the bacterial degradation of PFCs such as fluorobenzene (Carvalho et al., 2005), fluoroanilin (Amorim et al., 2013), PFB (Hughes et al., 2011), fluoroacetate (Davis et al., 2012), perfluorohexylethanol (Dinglasan et al., 2004; Wang et al., 2009; Liu et al., 2010) and perfluorohexylsulfonate (Wang et al., 2011). Some naturally occurring microorganisms possess defluorinating enzymes that attack the $\mathrm{C}-\mathrm{F}$ bond. Although PFOA-degrading bacteria have been isolated, their degradation efficiency is generally low, and strain resources are scarce. To address this problem, we isolated and identified a PFOAdegrading strain from the soil near a PFC production plant. Its growth and PFOA degradation performance were examined in order to optimize the degradation conditions and expand the microbial resources for treatment of PFOA.

\section{MATERIAL AND METHODS}

\section{Sample collection}

Six soil samples were collected near the PFC production plant in Wuhan China. The samples were sealed in sterile plastic bags and taken back to the laboratory under lowtemperature conditions. 


\section{Reagents and equipment}

Enzymes and reagents for genomic DNA extraction and PCR amplification were purchased from TaKaRa Biotechnology (Dalian) Co., Ltd.; PFOA, nonadecafluorodecanoic acid (PFDA) (99\% purity) and bis(trimethylsilyl)trifluoroacetamide (BSTFA) were purchased from Sigma Corporation (USA); and methyl tert-butyl ether (MTBE), normal hexane, and other analytically pure reagents were purchased from Hunan Scientific, Industrial and Trade Co., Ltd.

The equipments used were gas chromatograph-mass spectrometer (GC-MS; Agilent), UV spectrophotometer T6 (Shimadzu), high-speed refrigerated centrifuge (Eppendorf), and PTC-100MJR (Bio-Rad).

\section{Culture medium}

The enrichment culture medium contained $5 \mathrm{~g} / \mathrm{L} \mathrm{NH}_{4} \mathrm{NO}_{3}, 2 \mathrm{~g} / \mathrm{L} \mathrm{NaCl}, 1 \mathrm{~g} / \mathrm{L} \mathrm{KH}_{2} \mathrm{PO}_{4}$, $1 \mathrm{~g} / \mathrm{L} \mathrm{K}_{2} \mathrm{HPO}_{4}, 0.5 \mathrm{~g} / \mathrm{L} \mathrm{MgSO} \cdot 7 \mathrm{H}_{2} \mathrm{O}, 0.05 \mathrm{~g} / \mathrm{L} \mathrm{CaCl}_{2} \cdot 2 \mathrm{H}_{2} \mathrm{O}, 1 \mathrm{~g} / \mathrm{L}$ yeast extract, and 200,300 , 400 , and $500 \mathrm{mg} / \mathrm{L}$ PFOA, pH 7.0.

The inorganic salt culture medium contained $5 \mathrm{~g} / \mathrm{L} \mathrm{NH}_{4} \mathrm{NO}_{3}, 2 \mathrm{~g} / \mathrm{L} \mathrm{NaCl}, 1 \mathrm{~g} / \mathrm{L}$ $\mathrm{KH}_{2} \mathrm{PO}_{4}, 1 \mathrm{~g} / \mathrm{L} \mathrm{K}_{2} \mathrm{HPO}_{4}, 0.5 \mathrm{~g} / \mathrm{L} \mathrm{MgSO} \cdot 7 \mathrm{H}_{2} \mathrm{O}, 0.05 \mathrm{~g} / \mathrm{L} \mathrm{CaCl}_{2} \cdot 2 \mathrm{H}_{2} \mathrm{O}, \mathrm{pH} 7.0$, with the addition of different concentrations of PFOA as the sole carbon source.

The modified LB medium contained $10 \mathrm{~g} / \mathrm{L}$ peptone, $5 \mathrm{~g} / \mathrm{L}$ yeast extract, $10 \mathrm{~g} / \mathrm{L} \mathrm{NaCl}$, $500 \mathrm{mg} / \mathrm{L}$ PFOA, and $15-20 \%$ agar, $\mathrm{pH}$ 7.0.

\section{Acclimation, screening, and isolation of the PFOA-degrading strain}

Ten grams of soil sample was weighed, inoculated into $200 \mathrm{~mL}$ enrichment culture medium, and incubated under oscillation conditions of $30^{\circ} \mathrm{C}$ and $160 \mathrm{rpm}$. Every 7 days, $5 \%$ enriched liquid was transferred to fresh enrichment culture medium. The concentration of PFOA was increased gradually until it reached $500 \mathrm{mg} / \mathrm{L}$. Next, $10 \mathrm{~mL}$ bacterial liquid was transferred to $90 \mathrm{~mL}$ of an inorganic salt culture medium containing $500 \mathrm{mg} / \mathrm{L}$ PFOA as the only carbon source. Enriching and screening were performed with four successive transfers. After gradient dilution of $1 \mathrm{~mL}$ enriched bacterial liquid, the plate containing PFOA as the only carbon source was coated with bacterial liquid diluted at different rates. The bacteria were cultured at $30^{\circ} \mathrm{C}$, and streaking was performed for colonies in good growth condition. The purified strain was preserved in $15 \%$ glycerol at $-20^{\circ} \mathrm{C}$.

\section{Strain identification and PFOA-degrading characteristics of the strain Morphological, physiological, and biochemical features of the strain}

The PFOA-degrading strain was inoculated to LB medium and incubated at $30^{\circ} \mathrm{C}$ for $48 \mathrm{~h}$. The colony morphology was observed, and the physiological and biochemical features of the strain were determined via the literature (Dong and Cai, 2001).

\section{Phylogenetic analysis based on $16 S \mathrm{rRNA}$ gene sequencing}

Bacterial genomic DNA was extracted using the CTAB method. PCR amplification was carried out using the extracted DNA as a template and the universal 16S rRNA gene primers 
pA 5'-AGAGTTTGATCCTGGCTCAG-3' and PB 5'-TTAAGGTGATCCAGCCGCA-3'. The $50-\mu \mathrm{L}$ PCR system consisted of $10 \mathrm{ng}$ DNA template, $5 \mu \mathrm{L} 10 \mathrm{X}$ PCR buffer, $4 \mu \mathrm{L}$ dNTPs $(2.5$ $\mathrm{mM}), 1 \mu \mathrm{L}$ each primer $(20 \mu \mathrm{M}), 0.25 \mu \mathrm{L}$ Taq DNA polymerase $(5 \mathrm{U} / \mu \mathrm{L})$, and ionized water. PCR conditions were as follows: pre-denaturation at $95^{\circ} \mathrm{C}$ for $5 \mathrm{~min}$, denaturation at $95^{\circ} \mathrm{C}$ for $30 \mathrm{~s}$, annealing at $54^{\circ} \mathrm{C}$ for $30 \mathrm{~s}$, extension at $72^{\circ} \mathrm{C}$ for $90 \mathrm{~s}, 30$ cycles, and a final extension at $72^{\circ} \mathrm{C}$ for $10 \mathrm{~min}$. PCR products were sequenced by TaKaRa Biotechnology (Dalian) Co., Ltd.

The 16S rRNA gene sequences were submitted to GenBank, and an accession No. was obtained. Other 16S rRNA gene sequences with high homology were searched using BLAST on the GenBank/PEMBL/PDDBJ databases. Multiple-sequence alignment was performed using CLUSTAL-X. A Kimura model was used to estimate the phylogenetic distant matrix. A phylogenetic tree was constructed using the MEGA 4.0 software by the neighbor-joining method.

\section{Preparation of seed liquid of the PFOA-degrading strain}

A single colony was inoculated to modified LB medium and cultured at $30^{\circ} \mathrm{C}$ until it reached the log phase of growth. The thalli were collected by centrifugation and washed with sterile water three times. Subsequently, a bacterial suspension was prepared by adding an appropriate amount of sterilized water to achieve $\mathrm{OD}_{600}$ of about 1.5 , and this was used as seed liquid for subsequent tolerance and degradation experiments.

\section{Determination of tolerance of the strain to PFOA}

The seed liquid was inoculated to LB medium containing $0,500,1000,1500$, and $2000 \mathrm{mg} / \mathrm{L}$ PFOA at $2 \%$ inoculum. The bacteria were cultured under oscillation conditions of $30^{\circ} \mathrm{C}$ and $160 \mathrm{rpm}$. The $\mathrm{OD}_{600}$ value was determined by ultraviolet-visible spectrophotometer at 12 -h interval to assess the tolerance of the strain to PFOA. Three replicates were performed.

\section{Effect of environmental factors on the growth and PFOA-degrading performance of the strain}

A single-factor experimental design was adopted to assess the effect of the following factors: initial concentration of PFOA, inoculum amount, added nutrients, $\mathrm{pH}$, and temperature. The levels of each factor were set up as follows: 100, 300, 500, 800, and $1000 \mathrm{mg} / \mathrm{L} \mathrm{PFOA}$; $1,2,4,6$, and $8 \%$ inoculum; $1 \mathrm{~g} / \mathrm{L}$ yeast extract, $1 \mathrm{~g} / \mathrm{L}$ glucose, and $1 \mathrm{~g} / \mathrm{L}$ peptone as exogenous carbon sources; $\mathrm{pH}$ values $5,6,7,8$, and 9 ; temperatures of $15^{\circ}, 20^{\circ}, 25^{\circ}, 30^{\circ}, 35^{\circ}$, and $40^{\circ} \mathrm{C}$. The seed liquid was inoculated into inorganic salt culture medium under oscillation at 160 $\mathrm{rpm}$. For each factor, three replicates were set up. $\mathrm{OD}_{600}$ of the bacterial liquid and PFOA concentration were measured every $12 \mathrm{~h}$.

\section{Analysis method}

\section{Determination of bacterial cell concentration}

Bacterial cell concentration was measured by turbidimetry. The cell concentration was expressed as $\mathrm{OD}_{600}$; i.e., the optical density of the sample at $600 \mathrm{~nm}$. 


\section{Determination of PFOA in fermentation liquid}

The fermentation liquid was centrifuged at $5000 \mathrm{rpm}$ for $5 \mathrm{~min}$, and $5 \mathrm{~mL}$ supernatant was collected into a clean centrifuge tube. One milliliter of MTBE was added and oscillation extraction was performed for $10 \mathrm{~min}$. The liquid was stratified by standing and the organic phase was collected. The extraction was performed three times, the organic phase combined, and the extract liquor concentrated to dryness using sample concentrator. One milliliter of BSTFA was added to the tube with proper mixing. The tube was sealed and placed in a $40^{\circ} \mathrm{C}$ water bath for derivatization for $1 \mathrm{~h}$. The liquid was diluted to $10 \mathrm{~mL}$ using normal hexane, and GC-MS (selective ion monitoring, SIM) analysis was performed by the external standard method. The PFOA concentration was calculated from the standard curve of the concentration $v s$ the ratio of the peak area.

Conditions of GC-MS analysis were as follows: HP-5MS column $(30 \mathrm{~m} \times 0.25 \mathrm{~mm}$ x $0.25 \mathrm{~mm}$ ); column initial temperature $50^{\circ} \mathrm{C}$, retained for $2 \mathrm{~min}$, increased to $280^{\circ} \mathrm{C}$ at 25 $\mathrm{rpm}$, and retained for $2 \mathrm{~min}$; splitless injection; inlet temperature $280^{\circ} \mathrm{C}$; carrier gas: high-purity helium (99.999\%); flow rate $1.0 \mathrm{~mL} / \mathrm{min}$; injection amount $1 \mu \mathrm{L}$. MS conditions: EI ion source, ion source temperature $230^{\circ} \mathrm{C}$, quadrupole temperature $150^{\circ} \mathrm{C}$, aisle temperature $280^{\circ} \mathrm{C}$; full scan in the range of 50 to $600 \mathrm{amu}$, SIM modes $(\mathrm{m} / \mathrm{z})$ 119, 169, 319; solvent delay $4.0 \mathrm{~min}$.

\section{RESULTS}

\section{Morphological, physiological and biochemical features of the strain}

After acclimation and enrichment by a gradient concentration of PFOA, three strains that utilized PFOA as the only carbon source were screened. They were numbered YAB1, $\mathrm{YAB} 2$, and $\mathrm{YAB} 3$. YAB1 had faster growth and the highest PFOA degradation performance in the preliminary screening. YAB1 was inoculated to LB medium and cultured for 4 days. The colony diameter was $2.5-3.0 \mathrm{~mm}$, and its appearance was golden, round, and opaque with regular edges. After culture in inorganic salt culture medium containing PFOA as the only carbon source, the colony was small, light yellow, round, and opaque with regular edges. An optical microscope observation revealed that the strain was in the shape of a straight or slightly bent short rod. As far as physiological and biochemical characteristics were detected, the strain was identified as a Gram-negative and obligate aerobic bacterium. It could decompose glucose by oxidation and reduce nitrates by the secretion of oxidase and catalase. The strain was negative in a methyl red test and VP response, negative in starch and Tween- 80 hydrolysis tests, and positive in a gelatin liquefaction test, without producing benzpyrole or $\mathrm{H}_{2} \mathrm{~S}$.

\section{Phylogenetic analysis of YAB1}

Using the genomic DNA of YAB1 as a template, $16 \mathrm{~S}$ rRNA gene fragment was obtained by PCR amplification. The PCR products were then sequenced by the dideoxy-mediated chain termination method. After calibration, the sequences were submitted to GenBank (accession No. KT758848). Multiple-sequence alignment was performed and a phylogenetic tree was constructed using homologous sequences with high identity in public databases (Figure 1). It was found that YAB1 was highly homologous with Pseudomonas sp based on the $16 \mathrm{~S}$ rRNA gene sequence. YAB1 was clustered with Pseudomonas parafulva (NR 040859.1) in 
the same branch, showing identity as high as $99.86 \%$. According to colony morphology and its physiological and biochemical features, YAB1 was preliminarily identified as $P$. parafulva.

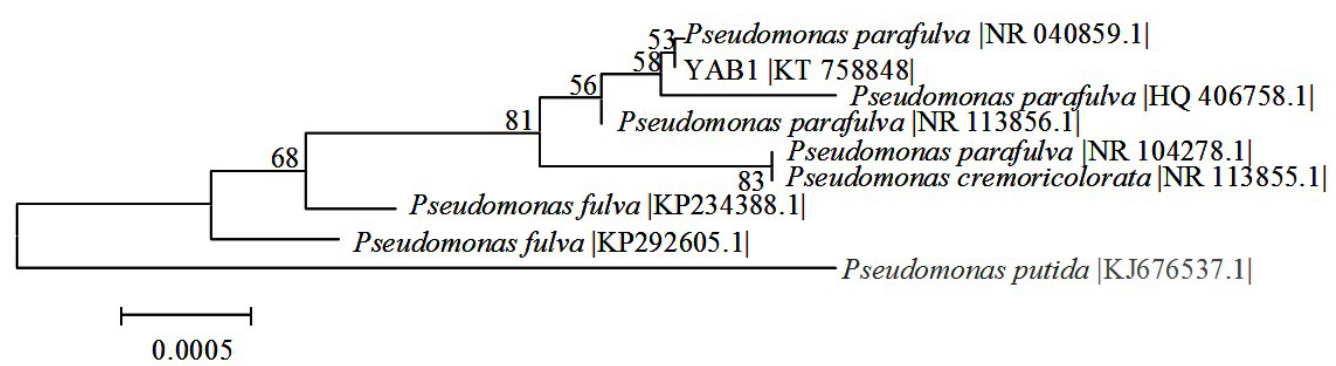

Figure 1. Neighbor-joining tree constructed based on 16S rRNA gene sequence analysis showing the phylogenetic relationships among strain YAB1 and other related taxa.

\section{Tolerance of YAB1 to PFOA}

The tolerance of YAB1 to PFOA is shown in Figure 2. The growth curve of YAB1 in the control group (PFOA concentration $0 \mathrm{mg} / \mathrm{L}$ ) was in line with the typical growth curve of the microbes. In LB medium containing $500 \mathrm{mg} / \mathrm{L}$ PFOA, YAB1 rapidly entered the log phase of growth, and $\mathrm{OD}_{600}$ reached a maximum of $2.170 \pm 0.177$ after $24 \mathrm{~h}$; the difference was not of statistical significance as compared to the control. The stationary phase of growth lasted for $60 \mathrm{~h}$, which was much longer than that of the control group. This indicated high tolerance of YAB1 to PFOA. In LB medium containing $1000 \mathrm{mg} / \mathrm{L}$ PFOA, the cell growth pattern was similar to that under $500 \mathrm{mg} / \mathrm{L}$ PFOA. However, the biomass decreased significantly, and the maximum $\mathrm{OD}_{600}$ was only $0.873 \pm 0.074$. We inferred that $1000 \mathrm{mg} / \mathrm{L}$ PFOA inhibited the growth of YAB1, but the strain still displayed considerable tolerance and growth adaptability. The strain barely grew at 1500 and $2000 \mathrm{mg} / \mathrm{L}$ PFOA. Thus, high concentrations of PFOA were toxic to the strain and greatly inhibited its proliferation. YAB1 generally had a strong tolerance to PFOA at low concentrations $(£ 1000 \mathrm{mg} / \mathrm{L})$; PFOA completely inhibited bacterial growth only at high concentrations $\left({ }^{3} 1500 \mathrm{mg} / \mathrm{L}\right)$.

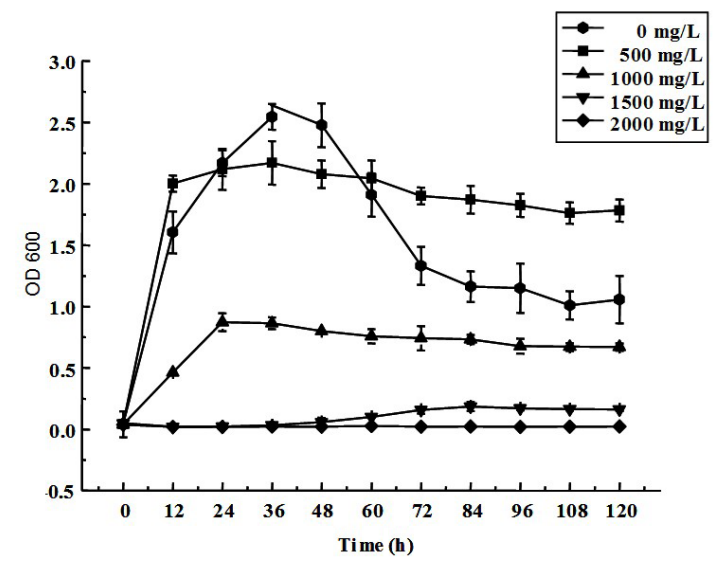

Figure 2. Growth curves of strain YAB1 in the presence of different concentrations of PFOA. 


\section{Growth and degradation performance of YAB1 under different environmental conditions}

\section{Effect of initial concentration of PFOA on the growth and degradation performance of the strain}

The effect of the initial concentration of PFOA on the growth and PFOA degradation performance of YAB1 is shown in Figure 3. When the PFOA concentration was less than 500 $\mathrm{mg} / \mathrm{L}$, the $\mathrm{OD}_{600}$ increased with increasing PFOA concentration; when PFOA concentration was greater than $500 \mathrm{mg} / \mathrm{L}, \mathrm{OD}_{600}$ decreased with the increasing PFOA concentration; and when the PFOA concentration was $500 \mathrm{mg} / \mathrm{L}$, the maximum $\mathrm{OD}_{600}$ was reached. Thus, 500 $\mathrm{mg} / \mathrm{L}$ was the optimal PFOA concentration for the growth of YAB1. PFOA is toxic to bacteria but also provides a carbon source for bacterial growth. Very high concentrations of PFOA inhibited the growth of YAB1, whereas very low concentrations were insufficient carbon sources and hence reduced the proliferation rate. As shown in Figure 3B, the biomass and degradation efficiency (32.4\%) were highest at a PFOA concentration of $500 \mathrm{mg} / \mathrm{L}$. The $\mathrm{OD}_{600}$ of cell concentration was $0.103 \pm 0.0051$ and the degradation rate was only $12.6 \%$ for 1000 $\mathrm{mg} / \mathrm{L}$ PFOA. This indicates that YAB1 had high tolerance to PFOA.

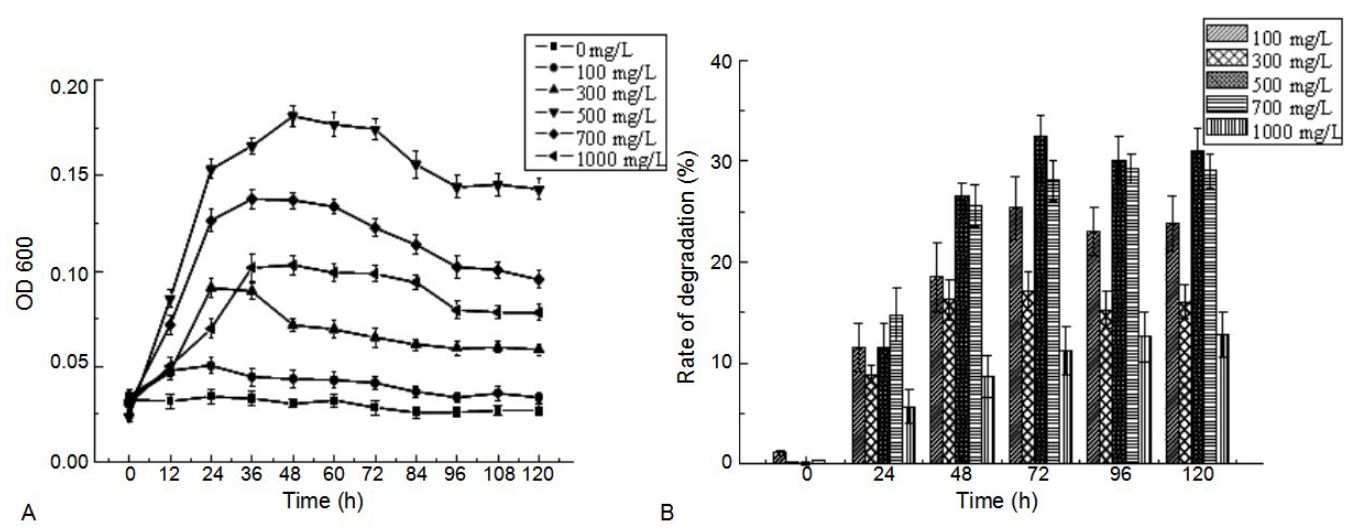

Figure 3. Effects of initial concentration of PFOA on the growth of strain YAB1 and degradation rate of PFOA.

\section{Effect of inoculum amount on the growth and degradation performance of the strain}

The effect of the amount of inoculum on the growth and degradation performance of YAB1 at a PFOA concentration of $500 \mathrm{mg} / \mathrm{L}$ is shown in Figure 4. At inoculum amounts of 1 and $2 \%$, the growth curve of YAB1 was the typical for the microbe. Biomass and degradation performance increased with increasing inoculum, since the larger the inoculum amount, the more metabolizing enzymes are produced by the strain in the presence of sufficient nutrients, which accelerates PFOA degradation. However, cell growth was significantly inhibited at exceeding an inoculum amount of $2 \%$. This is likely because of the high density of cells depleting the nutrients, so the strain could not proliferate rapidly or produce PFOA-degrading enzymes. Therefore, the optimal inoculum amount of YAB1 was $2 \%$. 

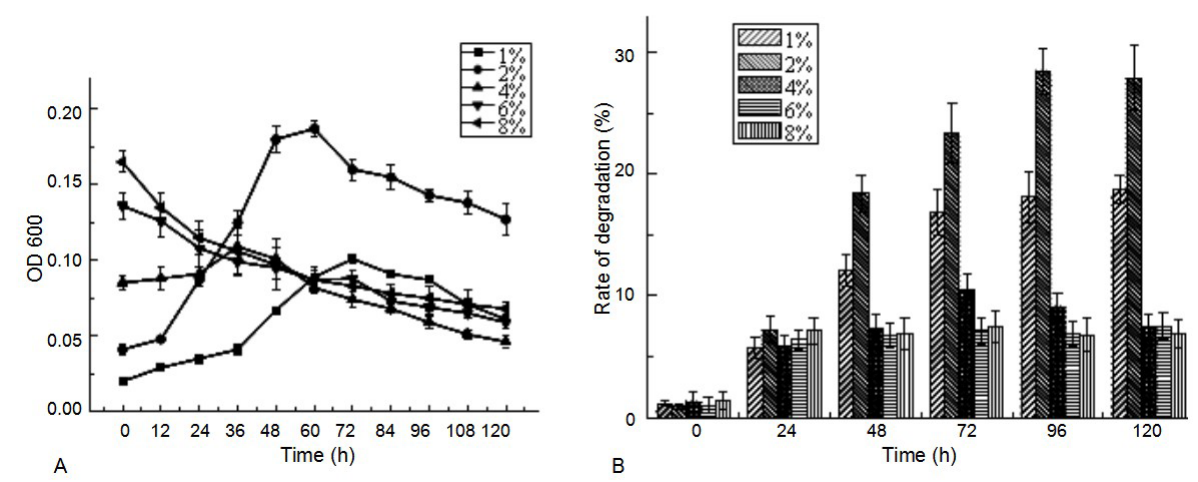

Figure 4. Effects of inoculum amount on the growth of strain YAB1 and degradation rate of PFOA.

\section{Effect of exogenous carbon sources on growth and degradation performance of the strain}

Glucose $(1 \mathrm{~g} / \mathrm{L})$, yeast extract $(1 \mathrm{~g} / \mathrm{L})$, and peptone $(1 \mathrm{~g} / \mathrm{L})$ were added to inorganic salt culture medium containing $500 \mathrm{mg} / \mathrm{L}$ PFOA to investigate the effect of carbon source on the growth and degradation performance of the strain. Figure 5A shows that yeast extract and peptone had a much significant growth-promoting effect than glucose. This may be because other nutrients were supplied to the strain when yeast extract and peptone components were added. As seen in Figure 5B, although the growth-promoting effect of glucose was not as great as those of yeast extract and peptone, its degradation-promoting performance was much higher, with maximum degradation rate of PFOA reaching $48.1 \%$. The strain may prefer yeast extract and peptone, which are compound nutrients, over PFOA, thereby resulting in fast thallus growth but low PFOA degradation. Glucose is a single nutrient, as glucose was consumed by the strain, PFOA became the major carbon source and the PFOA degradation rate increased. Therefore, glucose was the optimal exogenous carbon source for PFOA degradation by YAB1.
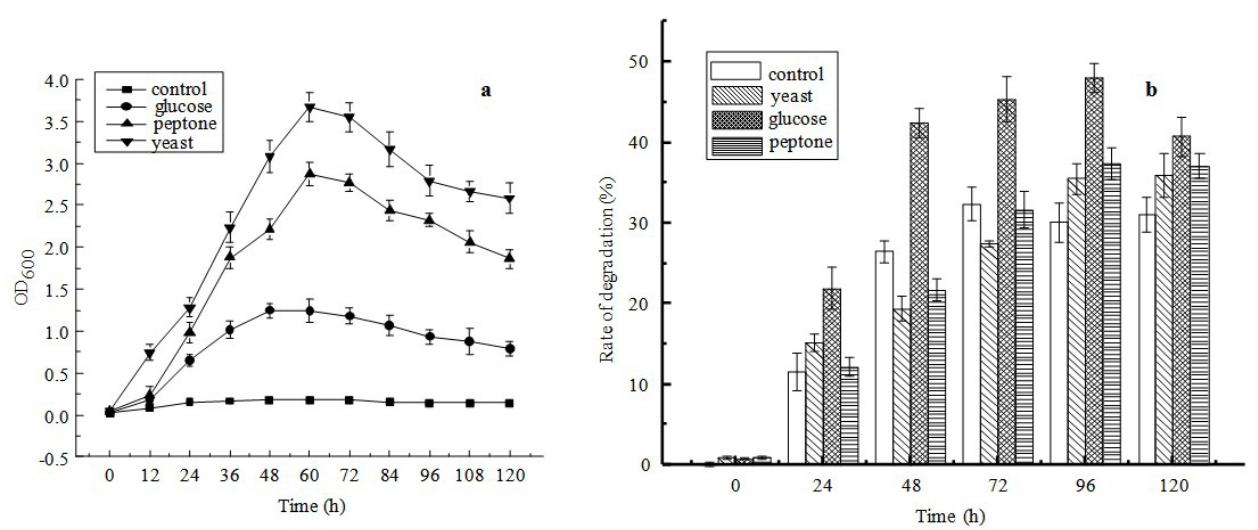

Figure 5. Effects of organic nutrients on the growth of strain YAB1 and degradation rate of PFOA. 


\section{Effect of $\mathrm{pH}$ value on growth and degradation performance of the strain}

Seed liquid of the strain was inoculated into inorganic salt culture medium containing $500 \mathrm{mg} / \mathrm{L}$ PFOA, and the effect of $\mathrm{pH}$ value on the growth and degradation performance of the strain was observed. As shown in Figure 6, the growth and degradation performance of YAB1 first increased then decreased with increasing $\mathrm{pH}$ value. At $\mathrm{pH} 5.0$, the $\mathrm{OD}_{600}$ and $\mathrm{PFOA}$ degradation rates were only 0.0613 and $4.1 \%$, respectively. The biomass and the degradation rate were higher at a $\mathrm{pH}$ of 6.0-8.0. Both reached a maximum at $\mathrm{pH} 7.0(0.181,28.9 \%)$. However, the biomass and PFOA degradation rate at $\mathrm{pH} 9.0$ did not differ significantly from those at $\mathrm{pH}$ 5.0. Thus, YAB1 can adapt to a wide range of $\mathrm{pH}$ values. The growth and degradation performance were higher at a $\mathrm{pH}$ of $6.0-8.0$, and the optimal $\mathrm{pH}$ was 7.0.
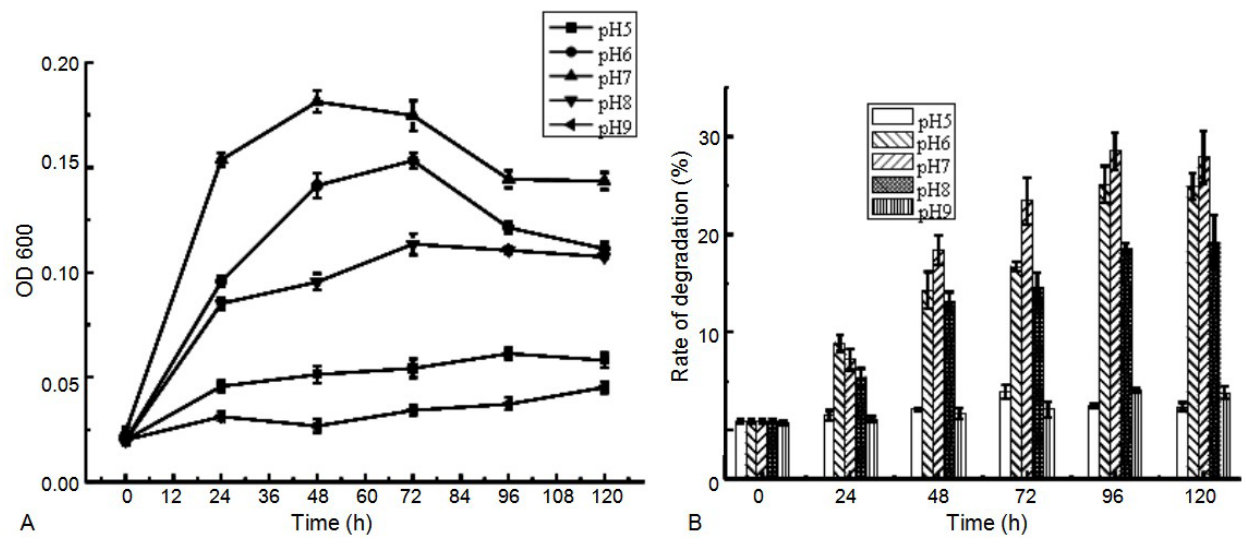

Figure 6. Effects of $\mathrm{pH}$ value on the growth of strain YAB1 and degradation rate of PFOA.

\section{Effect of temperature on the growth and degradation performance of the strain}

The growth and degradation performance of YAB1 at different temperatures are shown in Figure 7. Cell growth was very slow at $15^{\circ} \mathrm{C}$, and the degradation rate was extremely low. At $20^{\circ}$ to $35^{\circ} \mathrm{C}$, YAB1 proliferated rapidly. At $20^{\circ}$ and $25^{\circ} \mathrm{C}$, the biomass and the degradation rate were significantly lower than at $30^{\circ}$ and $35^{\circ} \mathrm{C}$. Both reached a maximum at $30^{\circ} \mathrm{C}$. Above $35^{\circ} \mathrm{C}$, cell growth and PFOA degradation were slightly inhibited compared to those at $30^{\circ} \mathrm{C}$. YAB1 experienced a short growth phase at $40^{\circ} \mathrm{C}$ but soon entered a declining phase with a low PFOA degradation rate. Temperature is an important environmental factor that determines the growth and proliferation of microbes. The growth of YAB1 first increased then decreased with increasing temperature. This pattern also applied to the degradation rate of PFOA. Thus, YAB1 cannot adapt to temperatures that are too low $\left(15^{\circ} \mathrm{C}\right)$ or too high $\left(40^{\circ} \mathrm{C}\right)$.

\section{DISCUSSION}

PFCs are a kind of novel persistent organic pollutants, and have reproductive toxicity, immunotoxicity, and neurotoxicity. Finding ways to degrade PFCs under normal temperature and normal pressure is imperative. Bioremediation techniques can be used to degrade pollutants in an environment-friendly way. However, the biodegradation of PFCs has been reported only 
in a few studies owing to their chemical stability and bio-inertia. We found references to the biodegradation of only the following pollutants in the literature: 8-2 fluorotelomer alcohol (Wang et al., 2009), 6-2 fluorotelomer alcohol (Liu et al., 2010), 6-2 fluorotelomer sulfonate (Wang et al., 2011), and $N$-ethyl perfluorooctane sulfonamidoethanol (Rhoads et al., 2008). The need to isolate highly efficient strains for degrading PFCs has become urgent. We isolated three strains that utilized PFOA as the only carbon source from the soil near a PFCs production plant. Among these, YAB1 had the strongest PFOA degradation ability. Based on morphology, physiological, and biochemical feature detection, and 16S rRNA gene sequencing, YAB1 was preliminarily identified as $P$. parafulva. The three strains isolated differed from the PFOAdegrading Klebsiella sp isolated by He et al. (2012), and from the PFOA-degrading strains Z1 (rod-like, white colony) and Z3 (filiform, producing purple blue toxin) obtained by Xue et al. (2004) through acclimation and screening. There are abundant PFOA-degrading microbes awaiting isolation in nature.
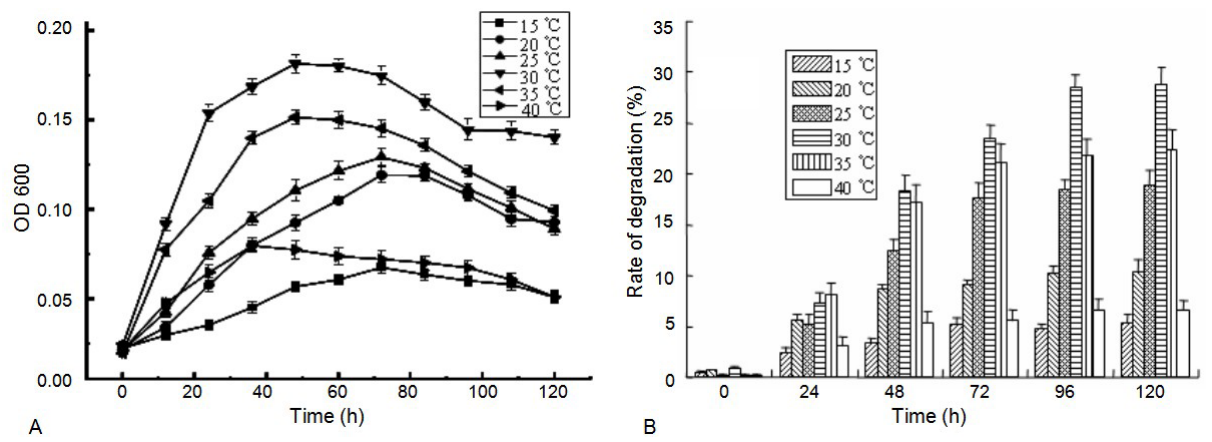

Figure 7. Effects of temperature on the growth of strain YAB1 and degradation rate of PFOA.

We investigated the effect of environmental factors on the growth and PFOA degradation performance of YAB1. Tolerance tests indicated that YAB1 could proliferate normally at $1000 \mathrm{mg} / \mathrm{L}$ PFOA. The strain was inhibited only when the PFOA concentration was greater than or equal to $1500 \mathrm{mg} / \mathrm{L}$. Xue et al. (2004) reported that the growth of PFOAdegrading strains $\mathrm{Z1}$ and $\mathrm{Z3}$ was inhibited at $1000 \mathrm{mg} / \mathrm{L}$ PFOA. We found that YAB1 had high tolerance to PFOA. A single-factor experiment was adopted to analyze the growth and degradation performance of YAB1. The optimal conditions for the thallus growth and PFOA degradation were as follows: optimal temperature, $30^{\circ} \mathrm{C}$; optimal $\mathrm{pH}$ value, 7.0 ; optimal inoculum amount, 2\%; optimal PFOA concentration, $500 \mathrm{mg} / \mathrm{L}$. When $1 \mathrm{~g} / \mathrm{L}$ glucose was added as a carbon source, the degradation rate of PFOA was 48.1\%. Although He et al. (2012) and Xue et al. (2004) isolated PFOA-degrading strains, they did not study their degradation performance on PFOA or any influencing factors. Schröder (2003) and Meesters and Schröder (2004) reported the degradation rate of PFOA by activated sludge. However, they used a microbial community for which there were many confounding factors, and the experiment had low repeatability. We studied the effect of environmental factors on cell growth and PFOA degradation using isolated strain YAB1, providing valuable data for the microbial degradation of PFOA.

Strain YAB1, identified as $P$. parafulva, showed high tolerance and degradation performance on PFOA. Like many other PFOA-degrading strains, it still had a long degradation cycle, low degradation efficiency, and incomplete degradation. To overcome these problems, 
we need to gain a comprehensive understanding of the mechanism of YAB1-degrading PFOA by a thorough analysis of the metabolic intermediates and products, and identification of PFOA-degrading related genes. Degradation performance on PFOA could be improved by genetic engineering and by optimizing the degradation conditions. This is an important step in applying bioremediation techniques for the microbial degradation of pollutants.

\section{CONCLUSIONS}

Three strains utilizing PFOA as the only carbon source were isolated, and YAB1 had the highest degradation performance. Based on morphology, physiological, and biochemical characteristic detection, and 16S rDNA sequencing, this strain was preliminarily identified as $P$. parafulva.

Tolerance tests on PFOA indicated that the maximum tolerated concentration of YAB1 was $1000 \mathrm{mg} / \mathrm{L}$ and the optimal PFOA concentration for the growth of YAB1 was $500 \mathrm{mg} / \mathrm{L}$.

The following optimal conditions were determined for cell growth and degradation performance: temperature, $30^{\circ} \mathrm{C} ; \mathrm{pH}, 7.0$; inoculum amount, $2 \%$; PFOA concentration, 500 $\mathrm{mg} / \mathrm{L}$. Yeast extract, peptone, and glucose, added as exogenous carbon sources, affected the cell growth and degradation rate of PFOA to varying extents. Yeast extract had the largest growth-promoting effect, with an $\mathrm{OD}_{600}$ of the bacterial liquid of $3.671 \pm 0.171$ at $60 \mathrm{~h}$; glucose had the largest degradation-promoting effect, with a maximum degradation rate of PFOA reaching $48.1 \%$.

\section{ACKNOWLEDGMENTS}

Research supported by the National Natural Science Foundation of China (Grant \#31260003), the Planned Science and Technology Project of Hunan Province, China (Grant \#2013FJ3025), and the Scientific Research Fund of the Hunan Provincial Education Department (Grant \#14C0937).

\section{REFERENCES}

Amorim CL, Carvalho MF, Afonso CMM and Castrol PML (2013). Biodegradation of fluoroanilines by the wild strain Labrys portucalensis. Int. Biodeter. Biodegr. 80: 10-15. http://dx.doi.org/10.1016/j.ibiod.2013.02.001

Carvalho MF, Ferreira Jorge R, Pacheco CC, De Marco P, et al. (2005). Isolation and properties of a pure bacterial strain capable of fluorobenzene degradation as sole carbon and energy source. Environ. Microbiol. 7: 294-298. http:// dx.doi.org/10.1111/j.1462-2920.2004.00714.x

Chen CL, Lu YL, Zhang X, Geng J, et al. (2009). A review of spatial and temporal assessment of PFOS and PFOA contamination in China. Chem. Ecol. 25: 163-177. http://dx.doi.org/10.1080/02757540902918321

Davis CK, Webb RI, Sly LI, Denman SE, et al. (2012). Isolation and survey of novel fluoroacetate-degrading bacteria belonging to the phylum Synergistetes. FEMS Microbiol. Ecol. 80: 671-684. http://dx.doi.org/10.1111/j.15746941.2012.01338.x

Dinglasan MJ, Ye Y, Edwards EA and Mabury SA (2004). Fluorotelomer alcohol biodegradation yields poly- and perfluorinated acids. Environ. Sci. Technol. 38: 2857-2864.http://dx.doi.org/10.1021/es0350177

Dong XZ and Cai MY (2001). Common Bacterial Systems Identification Manual. Ke Xue Chu Ban She, Beijing.

Grasty RC, Bjork JA, Wallace KB, Wolf DC, et al. (2005). Effects of prenatal perfluorooctane sulfonate (PFOS) exposure on lung maturation in the perinatal rat. Birth Defects Res. B Dev. Reprod. Toxicol. 74: 405-416. http://dx.doi. org $/ 10.1002 /$ bdrb.20059

He HT, Ma ZL, Luo HH, Yang L, et al. (2012). Microbial degradation of perfluorinated compounds. Zhong Guo Hua Xue Hui 12th Quan Guo Fu Hua Xue Hui Yi Lun Wen Zhai Yao Ji 2012: 64. 
Hori H, Nagano Y, Murayama M, Koike K, et al. (2012). Efficient decomposition of perfluoroether carboxylic acids in water with a combination of persulfate oxidant and ultrasonic irradiation. J. Fluor. Chem. 141: 5-10. http://dx.doi. org/10.1016/j.jfluchem.2012.05.012

Hughes D, Clark BR and Murphy CD (2011). Biodegradation of polyfluorinated biphenyl in bacteria. Biodegradation 22: 741-749. http://dx.doi.org/10.1007/s10532-010-9411-7

Kärrman A, Mueller JF, van Bavel B, Harden F, et al. (2006). Levels of 12 perfluorinated chemicals in pooled australian serum, collected 2002-2003, in relation to age, gender, and region. Environ. Sci. Technol. 40: 3742-3748. http:// dx.doi.org/10.1021/es060301u

Liu J, Wang N, Szostek B, Buck RC, et al. (2010). 6-2 Fluorotelomer alcohol aerobic biodegradation in soil and mixed bacterial culture. Chemosphere 78: 437-444. http://dx.doi.org/10.1016/j.chemosphere.2009.10.044

Luebker DJ, York RG, Hansen KJ, Moore JA, et al. (2005). Neonatal mortality from in utero exposure to perfluorooctanesulfonate (PFOS) in Sprague-Dawley rats: dose-response, and biochemical and pharamacokinetic parameters. Toxicology 215: 149-169. http://dx.doi.org/10.1016/j.tox.2005.07.019

Meesters RJW and Schröder HF (2004). Perfluorooctane sulfonate--a quite mobile anionic anthropogenic surfactant, ubiquitously found in the environment. Water Sci. Technol. 50: 235-242.

Ochoa-Herrera V, Sierra-Alvarez R, Somogyi A, Jacobsen NE, et al. (2008). Reductive defluorination of perfluorooctane sulfonate. Environ. Sci. Technol. 42: 3260-3264.http://dx.doi.org/10.1021/es702842q

Prevedouros K, Cousins IT, Buck RC and Korzeniowski SH (2006). Sources, fate and transport of perfluorocarboxylates. Environ. Sci. Technol. 40: 32-44. http://dx.doi.org/10.1021/es0512475

Rhoads KR, Janssen EML, Luthy RG and Criddle CS (2008). Aerobic biotransformation and fate of $N$-ethyl perfluorooctane sulfonamidoethanol (N-EtFOSE) in activated sludge. Environ. Sci. Technol. 42: 2873-2878. http:// dx.doi.org/10.1021/es702866c

Schröder HF (2003). Determination of fluorinated surfactants and their metabolites in sewage sludge samples by liquid chromatography with mass spectrometry and tandem mass spectrometry after pressurised liquid extraction and separation on fluorine-modified reversed-phase sorbents. J. Chromatogr. A 1020: 131-151. http://dx.doi.org/10.1016/ $\underline{\text { S0021-9673(03)00936-1 }}$

So MK, Taniyasu S, Yamashita N, Giesy JP, et al. (2004). Perfluorinated compounds in coastal waters of Hong Kong, South China, and Korea. Environ. Sci. Technol. 38: 4056-4063. http://dx.doi.org/10.1021/es049441z

Wang N, Szostek B, Buck RC, Folsom PW, et al. (2009). 8-2 fluorotelomer alcohol aerobic soil biodegradation: pathways, metabolites, and metabolite yields. Chemosphere 75: 1089-1096. http://dx.doi.org/10.1016/j. chemosphere.2009.01.033

Wang N, Liu J, Buck RC, Korzeniowski SH, et al. (2011). 6:2 fluorotelomer sulfonate aerobic biotransformation in activated sludge of waste water treatment plants. Chemosphere 82: 853-858. http://dx.doi.org/10.1016/j. chemosphere.2010.11.003

Xue XJ, Zhou YM, Wu M, Xue J, et al. (2004). Screening of Dominant Strains of Degrading Organo-fluorine Compounds. Huan Jing Ke Xue Yu Ji Shu 27: 11-12.

Zhao DM, Ding C, Xu XH and Hoffmann MR (2011). Kinetics of perfluorooctane sulfonate and perfluorooctanoate degradation by ultrasound irradiation. Hua Gong Xие Bao 62: 829-835. 